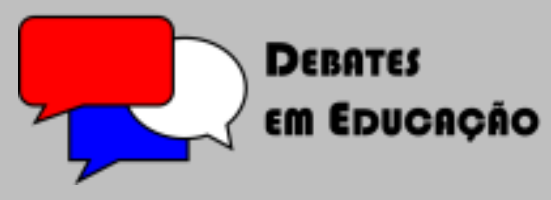

ISSN: $2175-6600$

Vol. 9 | №. 18 | Mai./Ago. | Ano 2017

\section{Elita Vanessa Ferreira Silva}

Faculdade Mauricio de Nassau (FMN) elitavanessa@hotmail.com

Nelma Camelo Araujo

Universidade Federal de Alagoas (UFAL) nelmacamelo@gmail.com

\title{
BIBLIOTECA ESCOLAR ENQUANTO ESPAÇO NO DESENVOLVIMENTO DE ATIVIDADES DE COIBIÇÃO DO BULL YING
}

\section{RESUMO}

O bullying tem como marca o desrespeito e a intolerância impregnados nas relações humanas dentro do contexto social. $E$ suas consequências para com as vítimas, os agressores e as testemunhas são irreversíveis pelo trauma causado, como também ocorre um prejuízo na aprendizagem dos alunos afetados por essa problemática. Assim, o presente ensaio pretende discutir a contribuição do profissional da biblioteca enquanto mediador no processo de coibir o bullying no contexto escolar, essa discussão foi realizada na Escola Municipal Luiza de França em União dos Palmares/AL, com a anuência registrada formalmente da direção da escola e a respectiva professora do Fundamental I. A professora orientou os alunos a responderem a um questionário sobre a percepção desses alunos sobre bullying, causas e atitude da escola na coibição dessa pratica, e também sobre a atuação do profissional da biblioteca em auxiliar a minimizar esse comportamento na escola. Os resultados apontaram que mesmo a escola não mantendo em seu quadro um profissional bibliotecário o espaço da biblioteca e em consonância com a literatura estudada, o profissional da biblioteca pode contribuir como mediador na coibição do bullying na escola, essa contribuição é possível mediante a parceria entre o profissional da biblioteca e os professores da escola junto com os pais dos alunos.

Palavras-chave: Biblioteca escolar. Bullying. Prevenção. Bibliotecário escolar. Mediação da leitura.

\section{SCHOOL LIBRARY AS A SPACE IN THE DEVELOPMENT OF BULLYING COHIBITION ACTIVITIES}

\begin{abstract}
Bullying has as the disrespect and intolerance impregnated in the human relations within the social context. And its consequences for the victims, the perpetrators and witnesses are irreversible by the trauma caused, as well as an injury on learning of the students affected by this problem. The present essay intends to discuss the professional contribution of the library as a mediator in the process to curb bullying in the school context, this discussion was held in the school hall Luiza of France in União dos Palmares/AL, with the agreement of the school formally registered and their elementary teacher $\mathrm{I}$. The teacher directed students to respond to a questionnaire about the perception of these students about bullying, causes and attitude of the school in halting this practice, and also about the activities of the professional library help to minimize this behavior at school. The results showed that even the school keeping your table a professional librarian and library space in line with the literature study, the library professional can help as a mediator in halting the bullying at school, this contribution is possible through the partnership between the library and the professional school teachers together with students ' parents.
\end{abstract}

Keywords: School library. Bullying. Prevention. School librarian. Reading mediation. 


\section{INTRODUÇÃO}

As crianças que praticam o bullying são vítimas dele também, pois elas não sabem a gravidade de seus atos para com os colegas de escola. Todos os envolvidos no contexto dessa prática precisam de ajuda, acompanhamento psicológico, professor, coordenador e direção da escola para tomarem as devidas providências.

Existem três tipos de personagens dessa temática: a vítima, o agressor e a testemunha. Estes personagens devem ter esse acompanhamento de intervenção para não se tornarem adultos sem limites com suas vidas desestruturadas.

A definição do que é, e do que não é o bullying, baseado em alguns autores (SANTANA, 2013; PEREIRA, 2011; FANTE, 2005; LOPES NETO, 2005) indica que o bullying dentro das escolas acontece de uma forma brusca e repetitiva, com o intuito de causar dor e sofrimento na vítima. São executados dentro de uma relação desigual de poder do forte contra o fraco com insultos, intimidações, apelidos cruéis, consequentemente levando-se à exclusão social, além dos danos materiais e físicos.

Essa distinção dos perfis de cada personagem é fundamental para que os pais e a escola observem o comportamento de seus filhos/alunos, verificando se eles fazem parte desse quadro de personagens, para assim evitar que as ocorrências aumentem, tomando medidas para a resolução da problemática.

No ambiente escolar e fora da instituição, a educação é vista como um dos processos de formação da pessoa humana. Processos esses através dos quais as pessoas se inserem na sociedade. $\mathrm{O}$ ambiente escolar precisa ser atrativo, voltado ao desenvolvimento da formação da consciência do indivíduo como um todo, para que os alunos da escola possam se sentir à vontade e poderem confiar e falar sobre o que ocorre com eles, se estão sendo vítimas ou não do bullying.

Avaliando uma brincadeira se ela fosse como bullying, esta pode dificultar a interação entre os alunos, limitando seu desenvolvimento e a vivência de experiências que são as bases para uma construção da cidadania. Muitos alunos tratam o bullying como uma brincadeira, mas quando são questionados a respeito dizem que não querem machucar seus colegas de sala e que é apenas uma brincadeira, mas na realidade praticam o bullying sem perceber da sua gravidade. Cabe à escola junto aos pais orientá-los, mostrando para os alunos/filhos outra forma de comportamento que estimulem a cooperação e a harmonia.

Se as ocorrências não forem repetitivas e intencionais não é considerada bullying, pois para ser classificada como bullying é necessário ter algumas características como: insultos, intimidações, apelidos cruéis, gozações que magoam profundamente, tomar 
pertences, meter medo, atuação de grupos que hostilizam, além dos danos físicos, morais e materiais. Esses comportamentos são repetitivos.

Com todos esses acontecimentos das ocorrências do bullying, percebe-se uma diferença de comportamento entre meninas e meninos. Por causa de seus perfis, esperase que os casos de bullying com meninas não tenham ocorrências, mas elas praticam com suas vítimas com atitudes de indiferença, isolamento e difamação de uma forma sutil com seus alvos. Já com os meninos a prática do bullying é feita com agressões físicas, ameaças, roubos, ofensas verbais contra as vítimas.

As escolas, para ter um bom desempenho contra essa temática, devem desenvolver estratégias de prevenção da mesma, pois é de fundamental importância o combate ao bullying, à parceria entre os pais e a escola, pois todo ato de bullying é ilícito, causando lesão à dignidade da pessoa humana, estando todos, poder público e cidadãos, obrigados a respeitar este direito constitucional.

Assim, a biblioteca escolar tem o papel de contribuir no ambiente escolar com o desenvolvimento e à formação dos alunos, por ser considerada a primeira biblioteca conhecida pela maioria das pessoas, e sendo responsável pelo primeiro contato com o livro e a leitura, pois educar um aluno é prepará-lo para a sociedade, educando-o a ser um agente transformador, participando da construção do seu conhecimento, como também dando condições para que sejam cidadãos éticos e capazes de não agredir ao próximo, evitando assim o avanço da violência dentro e fora do contexto escolar.

O profissional da biblioteca, conforme lei n 12244/2010, deverá ser o bibliotecário, aquele que está em constante questionamento, procurando atender sempre as necessidades de seus usuários, podendo contribuir para o surgimento de uma mudança social, fornecendo subsídios para a cooperação da disseminação da informação, sendo agentes sociais para tal transformação sociocultural.

É comum ter professores trabalhando dentro das bibliotecas, por não conseguirem dar aula, por estarem com problemas de saúde. Fazem isso por acharem que a biblioteca é um ambiente tranquilo, menos estressante. Se o professor chega a esse nível de estresse ele precisa cuidar de sua saúde adequadamente e voltar para a sala de aula, pois o profissional que atua na biblioteca deve contribuir para incentivar a leitura, fazer mediações junto aos alunos, disseminar a informação, ajudar em suas necessidades, tornando o ambiente da biblioteca um espaço agradável e para troca de conhecimento.

Diante do exposto esse ensaio apresenta o resultado de observação realizada em uma escola pública no interior de Alagoas, que teve como objetivo analisar o papel do 
profissional da biblioteca, enquanto mediador no processo de coibir o bullying no contexto escolar.

\section{BULLYING}

Conforme Pereira (2002, p. 7) o conceito de bullying é determinado por "[...] situações que, pela sua persistência e pelos níveis de violência física e psicológica, constituem fatores de risco que ameaçam gravemente o desenvolvimento psicológico e o bem-estar das crianças e jovens". Sendo assim, a repetitividade e o desequilíbrio de poder representado pela diferença de idade, de porte físico, de segurança ou de confiança, são fatores essenciais para a intimidação das vítimas.

Considerando essas características, o bullying pode ser definido como um conjunto de agressões intencionais e repetitivas provocadas por um agressor de maior poder ou força. Essas ações podem ser diárias ou semanais, como também ocorrer toda vez que o agressor encontrar a vítima, causando nela dor física ou emocional, abalando suas estruturas emocionais e seu psicológico.

De acordo com Meier (2013, p. 24) "a agressão só pode ser considerada bullying se for intencional e se, de alguma forma, incomodar a vítima”. Por exemplo: se um aluno usar uma palavra preconceituosa ou um palavrão para falar mal do colega de sala, trata-se de uma agressão, mas, se não for repetitiva, não será considerada bullying.

O bullying tem como marca o desrespeito, a intolerância e o preconceito impregnando nas relações humanas dentro da sociedade. As consequências dessa prática para os próprios estudantes é o prejuízo sobre aprendizagem, que tanto as vítimas como os agressores perdem o interesse pelo ensino, pois não se sentem motivados para ir à escola.

Esse fenômeno que vem causando um grande impacto no cotidiano escolar, muitos professores têm dificuldades em se posicionar frente a esta questão, isto porque, de fato, não estão conseguindo lidar com essa realidade que constantemente ocorre dentro dos muros da escola, tomando proporções arrasadoras junto os alunos/alvos.

Nesse contexto,

Os atos de bullying entre alunos apresentam determinadas características comuns: são comportamentos produzidos de forma repetitiva num período prolongado de tempo contra a mesma vítima; apresentam uma relação de desequilíbrio de poder, - que dificulta a defesa da vítima; ocorrem sem motivações evidentes; são comportamentos deliberados e danosos (FANTE, 2005, p.49 apud LYRA; PAZ, 2009, p. 20). 
Há diferenças quanto ao modo da prática do bullying entre os meninos e meninas por seus perfis. Com essa distinção, espera-se que as meninas sejam menos agressivas, com menos utilização de força; mas são mais dóceis e passivas, e para expressar seus sentimentos com as vítimas, elas utilizam meios mais discretos, não muito violentos comparados com as atitudes dos meninos junto à vítima (MEIER, 2013).

Os alunos que sofrem bullying diretamente acham que a culpa é deles, mas não conseguem fazer nada para impedi-lo. Eles podem até se afastar da vida social por medo de mais humilhação, como também podem sofrer danos psicológicos no seu dia a dia, podendo se machucar ou até desenvolver algum problema de saúde por causa dessa problemática. Essas crianças são mais propensas a faltar às aulas e até abandonar a escola, fazem tudo isso para evitar mais danos ao seu desenvolvimento psicológico. Com todos esses acontecimentos, sua autoestima baixa e, com o nível de agressões se agravando, essas crianças chegam a seu limite querendo até se vingar, usando a violência.

Por outro lado, as crianças que praticam bullying também são vítimas do mesmo. Elas precisam de ajuda, porque em alguns casos elas desconhecem a gravidade de seus atos. Essas crianças são mais propensas a se envolver em brigas e a ter um comportamento muito agressivo até chegar a sua vida adulta. Muitas vezes, vão mal na escola e até desistem de estudar, consequentemente são mais fáceis de terem problemas com a lei, pois o bullying só não atinge fisicamente como também moralmente, ferindo a sua integridade com intenção de intimidar e machucar sua essência com a intenção de causar sofrimento e dor, prejudicando sua saúde mental e psicológica. Consequentemente, tornando-se adultos sem limites, e com a vida desestruturada.

O aluno, ao sofrer a agressão, isola-se do contexto escolar, ou seja, em vez de se enturmar com os amigos de classe, ele se afasta cada vez mais por medo de sofrer uma nova agressão ou humilhação na frente dos outros. Isso só faz com que o indivíduo cresça aterrorizado de angústias e sofrimentos no seu convívio familiar como também escolar (PEREIRA, 2002).

Percebe-se que existem vários "personagens" envolvidos e que assumem vários papéis diferentes diante dessa problemática. Segundo Lopes Neto (2005, p.165), as crianças e adolescentes podem se envolver de três maneiras com o bullying, conforme o modo de agir perante a situação. Sendo assim, podem assumir os seguintes papéis: vítimas, agressores e testemunhas.

Por outro lado, a Associação Brasileira Multiprofissional de Proteção à Infância e à Adolescência (ABRAPIA) - propõe uma classificação ao denominar os alunos envolvidos 
com o bullying, isso para que não ocorra a intenção de não rotular os estudantes. A sua classificação foi feita dessa forma:

\footnotetext{
$\checkmark$ Alvos de bullying (vítimas): constituem esse grupo os discentes que só sofrem;

$\checkmark$ Alvos/autores de bullying (agressores/vítimas): constituído de discentes que tanto sofrem como também praticam;

$\checkmark$ Autores de bullying (agressores): constituído de discentes que apenas praticam;

$\checkmark$ Testemunhas de bullying: constituído pelos alunos que apenas observam e convivem com a situação. (LYRA; PAZ, 2009, p. 21).
}

Essas distinções dos perfis irão auxiliar a escola e os pais dos alunos a identificarem no comportamento de seus filhos/alunos, em quais perfis ele se enquadra no contexto escolar e, com isso, tentar ajudá-lo, pois aqueles que praticam o bullying contra seus próprios colegas de sala poderão levar para a vida adulta o mesmo comportamento e, consequentemente, irão ter atitudes agressivas no contexto familiar.

De acordo com Lyra; Paz (2009, p. 13) "são pessoas que os alvos/autores acreditam serem inferiores, ou seja, tornam-se 'presas fáceis' aqueles que não parecem capazes de revidar as suas agressões, provocações, intimidações”.

De acordo com a literatura existem vários tipos de bullying. Mas nessa pesquisa só será levantada dois tipos de bullying: o psicológico, que amedronta, discrimina, exclui as vítimas do grupo, fazem com que suas vítimas sofram humilhações; o físico, que agride, bate, fere, persegue e rouba suas vítimas, deixando-as com medo de reagir às agressões, pois temem sofrer represálias ainda mais fortes. Essas duas práticas juntas, tornam-se mais perigosas e arriscadas para o psicossocial das vítimas, pois elas se tornarão adultos com pouca autoestima e sem nenhum convívio social por causa do medo.

\subsection{O Bullying no contexto escolar}

A violência escolar tem sido um dos quadros mais alarmantes da educação, onde esta se refere ao comportamento dos estudantes quando praticam xingamentos com os professores, como também com seus próprios colegas de sala, fazem também uso dessa prática com chutes, muros e alguns casos corriqueiros dentro do âmbito escolar (LOPES NETO, 2005).

O comportamento agressivo ou violento dentro do contexto escolar às vezes é produzido de acordo com o que a criança vivência no cotidiano, o seu modelo educativo construído ao longo da sua vida em seu ambiente familiar, pois os papéis dos pais são de fundamental importância para a educação de seus filhos e suas atitudes irão dar exemplos a eles, e muitas vezes prejudicam seu desenvolvimento tornando-se crianças agressivas, 
pois se os pais não dão carinho e atenção adequada, pode surgir uma carência afetiva e consequentemente uma desestruturação familiar. Isso só irá contribuir para que o aluno/filho se desinteresse da escola, deixe de ver a escola como um ambiente para adquirir conhecimento e só a frequente para maltratar e agredir seus colegas, fazendo com que o espaço escolar se torne nada amistoso, nem agradável.

Sofrendo humilhações e ameaças, degradando sua imagem que afetam seu estado emocional, a vítima procura o Conselho Tutelar, órgão responsável pelos jovens e adolescentes. Lá ela tenta buscar uma solução para proteger sua integridade, servindo como base para auxiliar no acompanhamento das vítimas (FANTE 2005, apud LYRA; PAZ, 2009).

Os direitos garantidos no Cap. II, Art. $17^{\circ}$ do Estatuto da Criança e do Adolescente (1991) que consiste na inviolabilidade da integridade física, psíquica e moral da criança e do adolescente, abrangendo a preservação da imagem, da identidade, da autonomia, dos valores, das ideias, das crenças, dos espaços e dos objetos pessoais, parecem estar sendo cada vez mais silenciados por cenários de violência e bullying.

Acredita-se que a escola é o lugar onde o bullying pode crescer de forma indiscriminada. Caso ele não seja controlado a tempo, pode trazer prejuízos não só ao ambiente escolar, como também para toda comunidade.

Entretanto, é importante frisar que este fenômeno não é recente. Ao pensarmos sobre o tempo em que frequentávamos a escola como alunos, certamente virá à mente casos de "brincadeiras" entre os alunos, que hoje é identificado como bullying. Essas situações de violência podem ter produzido traumas que interferem ou interferiram na construção das identidades de cada aluno.

Tanto os pais como os alunos, os professores, e coordenadores da escola defendem medidas mais duras para com os alunos que cometem atos irregulares como, por exemplo, a expulsão. Dentro desse contexto das discussões, chamou-se atenção para entrada de armas de fogo no ambiente escolar e que deveria ser feita revistas na entrada do colégio para coibir a violência.

A biblioteca escolar é geralmente o primeiro contato da criança com uma unidade de informação. Pimentel, Bernardes e Santana (2007, p. 23) abordam que biblioteca escolar.

[...] localiza-se em escolas e é organizada para integrar-se com a sala de aula e no desenvolvimento do currículo escolar. Funciona como um centro de recursos educativos, integrado ao processo de ensino-aprendizagem, tendo como objetivo primordial desenvolver e fomentar a leitura e a informação. Poderá servir também como suporte para a comunidade em suas necessidades. 
A biblioteca escolar deve contar com bibliotecários preparados tanto tecnicamente, como também como agentes educadores das crianças e adolescentes, capazes de realizar atividades de lazer e cultura dentro do ambiente escolar.

Nessa direção, deparamo-nos num contexto conturbado onde as famílias são constituintes do eixo central da sociedade, e já não refletem mais o sinônimo de educação e paz. Isto acontece por causa da corrida pelos meios de sobrevivência, fazendo com que as famílias percam sua identidade e gerem filhos sem vínculos afetivos, sem princípios.

A educação deve ser desenvolvida e fundamentada nos 04 pilares (saber ser, saber fazer, saber aprender e saber viver e conviver), envolvida na realização do educando para o desenvolvimento intelectual e o exercício da cidadania. A filosofia da escola deve estar voltada para o preceito de humanização, para o relacionamento do cotidiano, uma educação transformadora, com um compromisso para alcançar a todos dando total assistência durante os ocorridos dessa problemática. É importante que a escola tenha uma postura a essas práticas de bullying, fazendo com que seus alunos percebam o grau de risco da prática com seus colegas.

Nesse sentido, a educação é vista como um dos processos de formação da pessoa humana, processos através dos quais as pessoas se inserem na sociedade; pela educação desenvolvemos nossa capacidade e potencialidade para o "saber e para o fazer", no processo de educação está presente a dinamicidade de muitas ações e relações entre pessoas e grupos que podem fazer desse processo um mecanismo capaz de produzir transformações sociais e culturais.

Tendo em vista que a escola exerce um papel primordial para a formação da sociedade e do homem como um todo, a relação escola/sociedade deve ser de modo interativo, pois sua filosofia deve ser coerente, voltada para o processo de inclusão social e educacional, formadora de seres participativos, críticos, reflexivos e transformadores. É importante frisar que a escola tem como responsabilidade desenvolver um trabalho digno, resgatando os valores para o bem da coletividade.

O ambiente escolar torna-se, portanto, atrativo, voltado ao desenvolvimento da consciência crítica, visando sempre o conhecimento e prática de direitos e deveres na formação do educando, visto como ambiente prazeroso, mais solidário, menos burocrático. Portanto, um ambiente que leva em conta a contextualização do conjunto das dimensões da formação humana, onde o conhecimento é socializado, possibilitará uma tarefa fundamental na formação de seres humanos críticos, reflexivos e capacitados para o exercício da cidadania como um todo. 


\section{O BIBLIOTECÁRIO E O BULL YING}

O Bibliotecário é visto como mediador da informação de seu usuário, contribuindo para que este possa ser informado e fazer uso adequadamente da informação que necessita/busca. Sobre esse aspecto o bibliotecário pode auxiliar os professores e gestores escolares não apenas em repassar informações sobre o que venha a ser bullying, mas também colaborar em atividades que venham a coibir essa prática nas escolas seja elas com atividades ou no auxílio a esse corpo de funcionário das escolas em melhorar suas ações para coibição de bullying. Assim, este capítulo visa registrar, após leituras realizadas sobre o perfil do bibliotecário e como ele pode agir para auxiliar na coibição do bullying na escola.

Enquanto educador, o bibliotecário contribui no planejamento, organização e implantação de bibliotecas. Seu papel é encontrar a informação, facilitando seu acesso, ensinando e auxiliando ao usuário a obter o conhecimento, principalmente se este fizer uso de toda sua capacidade e potencial para desempenhar o seu trabalho.

O papel do bibliotecário seria o de intermediar as ações de comunicação da informação, agindo na estrutura do processo, estando entre o emissor/produtor do conhecimento e o receptor/consumidor do conhecimento gerado, identificando e atendendo às necessidades informacionais de seus usuários, sejam imediatos ou potenciais, estabelecendo uma dinâmica entre os repositórios estáticos do conhecimento e as questões dos indivíduos na busca de conhecimento. (ODDONE, 1998, p.2 apud ANTONIO; MORAES, 2008, p. 320).

Os bibliotecários podem contribuir para o surgimento de uma mudança social, se eles fornecerem subsídios para a cooperação da disseminação da informação, sendo agentes sociais para tal transformação sociocultural. Esses subsídios são de fundamental importância para o aprendizado como também na evolução da personalidade do indivíduo, pois ajudará o acompanhamento dos usuários auxiliando no fornecimento das informações necessárias durante seu estudo.

O bibliotecário escolar tem uma tarefa diferenciada, ou seja, além de dominar as técnicas, planejamento e organização da unidade de informação, ele tem a função de cativar e conquistar os alunos, tornando-se assim mais comunicativo e participativo com as atividades da instituição que atua. (MORAES, 2014, p. 25).

Os serviços oferecidos pelos bibliotecários para incentivar a leitura são muito importantes, pois eles são integrados ao processo de ensino-aprendizagem dentro do contexto escolar. Conforme (HILLESHEIM, FACHIN, 2003/2004, p. 4 apud EDUVIRGES, 2012) "[...] favorecem o desenvolvimento e consolidação do hábito de leitura nas crianças 
e do senso crítico, pois é nesta fase inicial da vida escolar que se criam as raízes e o fortalecimento do ser humano como um ser consciente e crítico do espaço que ocupa".

É importante que o bibliotecário escolar interaja junto com os alunos para criar essas raízes ajudando o fortalecimento do seu crescimento e desenvolvimento social junto com os colegas de sala; que participe do seu convívio e, consequentemente, ganhe a confiança deles e com isso facilitará seu trabalho de acompanhamento com os envolvidos dessa prática.

Caldin (2005, p. 165) afirma que "as ações desenvolvidas pelo bibliotecário escolar visam à educação em um sentido amplo, incluindo, aí, a formação de hábitos e atitudes dos alunos". Essas ações podem ser desempenhadas pelo bibliotecário para incentivar a leitura dentro e fora do espaço da biblioteca, consequentemente irá conseguir que os alunos obtenham um hábito de leitura, como também irá tornar uma atividade prazerosa.

De acordo com LOPES NETO; SAAVEDRA (2003 apud MORAES, 2014, p. 29) seguindo o objetivo do Programa Educar para a Paz, notou-se que o bibliotecário pode atuar na prevenção ao bullying, disponibilizando o espaço físico da biblioteca para:

a) Montar estantes e cartazes informativos;

b) Separar o acervo referente aos temas bullying e violência escolar e montar um catálogo para consulta do tema;

c) Trabalhar junto aos professores e alunos a literatura sobre o tema, desenvolvendo trabalhos de conscientização acerca do bullying e violência escolar; d) Fazer com que a hora do conto seja voltada para histórias da temática bullying e violência escolar;

e) Abrir a biblioteca na hora do recreio e incentivar os alunos a frequentarem, por exemplo, para renovação ou empréstimo de livros;

f) Deixar o espaço do recreio para debates.

É um programa que tem como objetivo práticas de incentivo à solidariedade junto ao próximo, como também superação dessa prática. Ele busca fazer a prevenção do fenômeno antes que ele se alastre demasiadamente dentro do contexto escolar. Durante o desenvolvimento desse programa, os alunos são conscientizados da prática como também de suas consequências em seu desenvolvimento social. Uma excelente estratégia de combater essa prática é a promoção de debates com os pais, professores, coordenadores, diretores e bibliotecários, tendo momentos que podem ser trocadas experiências junto aos jovens, identificando com suas experiências quem são suas vítimas, agressores e testemunhas. A prática do bullying junto aos alunos/jovens viola o direito à educação, à segurança, ao desenvolvimento, à saúde e à sobrevivência.

O programa de enfrentamento ao bullying escolar, Educar para a Paz, desenvolvido pela pesquisadora, Cléo Fante, tem por objetivo sensibilizar a comunidade escolar para a relevância do problema e a necessidade de enfrentamento por meio de ações promotoras da cultura de paz. Objetiva também incentivar a criação de leis, políticas públicas e investimentos contra o bullying e proteção integral à criança e ao 
adolescente, por entender que a violência em suas diversas formas representa uma violação dos direitos humanos da criança, em especial os direitos à integridade física, dignidade humana e igual proteção perante a lei. (FANTE, 2010, p.5).

A intervenção deve visar o trabalho individual dos personagens dessa prática, como também os pais devem ser incluídos no sentido de desenvolver comportamentos para reduzir essa problemática. É preciso combater esse tipo de violência e proteger as crianças, propiciando um lugar seguro para se desenvolverem. A importância do programa antibullying "educar para paz", não pode ficar apenas no espaço escolar, mas também buscar outras atividades, como artísticas e esportivas, buscando o interesse dos alunos, inserindo a temática em vários campos da educação.

De acordo com Valentim (2000, p. 116) "O perfil ideal do profissional bibliotecário é contingencial ao ambiente e à sociedade onde atua, o que significa que, traçar um perfil é delinear as possibilidades de desempenho e crescimento pessoais e profissionais".

O bibliotecário que atua em uma biblioteca escolar precisa ser um pesquisador, um educador e agente socializador das necessidades de sua comunidade, verificando as causas para suprir as necessidades da comunidade, criando assim estratégias específicas para o atendimento ao seu público alvo, participando do desenvolvimento do indivíduo e da sociedade, fazendo com que seu espaço escolar torne-se um ambiente de convivência às vítimas agredidas do bullying, pois os alunos se sentirão seguros e confiantes para continuar sua jornada escolar.

O seu trabalho na biblioteca deve enriquecer o aprendizado da sala de aula, fornecendo subsídios para o aluno encontrar as ferramentas necessárias para aprofundar os seus conhecimentos através de pesquisas e estimular o seu desenvolvimento cultural. (SILVA, 2005, p. 77).

Contudo, as escolas, para obter um bom desempenho em sua problemática, devem desenvolver estratégias para uma diminuição ou até mesmo a prevenção do mesmo. Pois, seria de fundamental importância ao combate ao bullying à união, como também a cooperação entre os integrantes da comunidade escolar para desprender esta violência.

Conforme Bernardi; Barros (2008, p. 02 apud QUERINO, 2013) apresentam como perfil desejado do bibliotecário:

O profissional diferenciado precisa ser ágil; dinâmico; pró-ativo; bem informado; diplomata; atualizado; audacioso; curioso; "antenado" em tudo o que se passa ao seu redor; "ter jogo de cintura" para driblar situações; ter um pouco de bruxo, sem perder a pose de fada; saber se relacionar com pares e com o público em geral; ser organizado; deve criar e manter um clima agradável e de convívio propício aos usuários da biblioteca.

Para que a biblioteca beneficie a comunidade escolar, ela precisa definir metas e alcançar os propósitos de sua missão. Como ajuda para tanto, tem-se o Manifesto da 
Organização das Nações Unidas para a Educação, Ciência e Cultura (UNESCO) / Federação Internacional de Associações e Instituições Bibliotecárias (IFLA) para bibliotecas escolares.

O Manifesto da IFLA/UNESCO informa que a biblioteca escolar deve apresentar os seguintes objetivos:

$>$ Apoiar e intensificar a consecução dos objetivos educacionais definidos na missão e no currículo da escola;

$>$ Desenvolver e manter nas crianças o hábito e o prazer da leitura e da aprendizagem, bem como o uso dos recursos da biblioteca ao longo da vida;

$>$ Oferecer oportunidades de vivências destinadas à produção e uso da informação voltada ao conhecimento, à compreensão, imaginação e ao entretenimento;

> Apoiar todos os estudantes na aprendizagem e prática de habilidades para avaliar e usar a informação, em suas variadas formas, suportes ou meios, incluindo a sensibilidade para utilizar adequadamente as formas de comunicação com a comunidade onde estão inseridos;

$>$ Prover acesso em nível local, regional, nacional e global aos recursos existentes e às oportunidades que expõem os aprendizes a diversas ideias, experiências e opiniões;

$>$ Organizar atividades que incentivem a tomada de consciência cultural e social, bem como de sensibilidade;

> Trabalhar em conjunto com estudantes, professores, administradores e pais, para o alcance final da missão e objetivos da escola;

$>$ Proclamar o conceito de que a liberdade intelectual e o acesso à informação são pontos fundamentais à formação de cidadania responsável e ao exercício da democracia;

> Promover leitura, recursos e serviços da biblioteca escolar junto à comunidade escolar e ao seu derredor (FEDERAÇÃO INTERNACIONAL DE ASSOCIAÇÕES DE BIBLIOTECÁRIOS E INSTITUIÇÕES, 2002, p. 2-3 apud QUERINO, 2013, p. 20).

Assim, o bibliotecário precisa ter habilidade para perceber e aceitar mudanças, e a forma tradicional que ele utilizava para administrar deve estar sempre aliada a isso. É importante proporcionar também oportunidades diversas para os usuários obterem as informações desejadas, como também terem o contato com toda e qualquer leitura disponível dentro e fora da biblioteca. Conhecendo o mundo da leitura e do conhecimento ao seu redor, tornando-se um indivíduo capaz com senso crítico.

Segundo Caldin (2005, p. 166), "além de despertar o gosto pela leitura como forma habitual de lazer, um dos objetivos da biblioteca escolar é a formação do cidadão consciente e capaz de um pensamento crítico e criativo". Assim, a leitura pode seduzir e informar, cativar o leitor e ajudar na formação cidadã.

O ideal para que o processo de promoção da leitura estivesse presente em cada escola, e que tivessem uma biblioteca equipada e contasse no quadro de funcionários com a presença de um bibliotecário. Assim, a biblioteca escolar poderia oferecer um suporte pedagógico maior tanto para os professores como para os alunos, seja por meio do acervo atualizado, como também pelo profissional habilitado e qualificado, contribuindo assim no 
processo de ensino-aprendizagem da escola. Infelizmente esse cenário de um ideal das bibliotecas escolares não faz parte da realidade brasileira.

A biblioteca escolar, segundo Silva (2006a, p. 50) "É a base para a formação de leitores, porém a sua importância deve sair do papel para transformar-se em realidade".

Contudo, não basta existir projetos governamentais ou institucionais. É de fundamental importância a existência de biblioteca dentro das escolas, porque o que acontece em algumas escolas nem se quer existe e sim apenas uma sala de leitura pequena amontoada de livros fazendo-se como depósito. A visão de biblioteca dentro da sociedade precisa urgentemente entender seu significado e importância dentro do contexto escolar e não ser vista como apenas mera guardiã de livros.

Significa também dizer que o Estado precisa investir em projetos de incentivo à leitura, que a biblioteca escolar seja vista com outros olhos e que tanto a escola e sua comunidade escolar invistam em uma interação entre professores e bibliotecários com o intuito de incentivar práticas de leitura.

\section{$4 \quad$ LOCUS DO ENSAIO}

Tomou-se como Locus para o ensaio a Escola Municipal Luiza de França em União doa Palmares/AL, um Município de destaque no Estado de Alagoas, pois conta com o incentivo do poder público no desenvolvimento de atividades culturais.

A Escola possui turmas da Educação Infantil e do ensino fundamental 1, no horário matutino tendo as turmas da educação infantil ao $4^{\circ}$ ano, e no horário vespertino educação infantil e o $5^{\circ}$ ano, totalizando 331 alunos.

A turma indicada pela direção da escola para realização do trabalho foi a do $4^{\circ}$ Ano, contendo 23 alunos, sendo 14 meninos e 9 meninas. A seleção da citada turma se deu em função da faixa etária e desenvolvimento cognitivo. Todo os procedimentos tiveram anuência (autorização formal) da direção da escola e a respectiva professora da turma indicada.

A biblioteca da escola funciona de segunda a sexta, das 7 h50min às $11 \mathrm{~h} 30 \mathrm{~min}$ e das $13 \mathrm{~h} 00 \mathrm{~min}$ às $17 \mathrm{~h} 30 \mathrm{~min}$. Seu acervo é composto por livros didáticos voltados para seu respectivo público: a Educação Infantil e o Ensino Fundamental 1, com livros infantis para atender à educação infantil. A literatura infantil é exposta livremente, para que os usuários tenham a liberdade de escolher os livros que desejam. A/o responsável pela biblioteca não é uma bibliotecária e sim uma professora afastada da sala de aula. Para fins do ensaio, foi utilizado um questionário com perguntas fechadas e abertas, sendo entregue à professora, 
para que a mesma auxiliasse seus alunos no entendimento do porquê da aplicação do mesmo. A estrutura do questionário foi construída com nove questões, identificando o perfil desses alunos e o conhecimento dos mesmos sobre o assunto, bem como a existência do bullying naquela escola.

De acordo com as respostas, em relação ao perfil dos alunos (que correspondem as questões de 1 a 3 obteve-se as seguintes informações: meninos de 9 a 14 anos e meninas de 9 a 10 anos.

Quando investigados sobre se o bullying pode "prejudicar o aprendizado escolar", $100 \%$ dos alunos responderam que sim, e todos justificaram suas respostas. Desta forma, observar-se que, o bullying prejudica o aprendizado dos mesmos no ambiente escolar. Segundo a fala de um dos alunos que respondeu o questionário: "O motivo de desejar vingança pode prejudicar o aprendizado [dos alunos]". Já para outro aluno: "O bullying leva a violência e prejudica a vida escolar".

Diante das informações dos alunos LOPES NETO (2005, p.35) acrescentou que: "O bullying é mais prevalente entre alunos com idades entre 11 e 13 anos, sendo menos frequente na educação infantil e ensino médio". A faixa etária é importante no trabalho, pois, como pesquisado, é um recorte mostrando que nessa faixa onde ocorre com frequência casos de bullying.

As vítimas da prática de bullying apresentam mudanças comportamentais permitindo o reconhecimento do que está acontecendo para os professores, coordenadores, diretores e bibliotecário. Por isso é preciso ficar alerta. Porém, a maioria dos casos de agressão acontece na adolescência por causa das mudanças físicas comportamentais dos alunos que acabam se tornando alvos fáceis para os agressores dentro do seu contexto escolar.

Em relação à questão se o aluno "já presenciou alguma situação de bullying na escola?" Os mesmos mencionaram o que haviam presenciado.

Dos sete alunos do sexo masculino que afirmaram terem presenciado situação de bullying na escola, descreveram essas atividades, sendo elas: apelidar os colegas, chamar de ("carequinha"), ("quatro olhos"), xingamentos, bater; já em relação às meninas, as mesmas consideram a situação de bullying como: apelidos, (“magras"), ("gordas"), ("loucas"), ("Maria Joaquina”) (metida), etc. Conforme a fala de uma aluna, se já presenciou alguma situação de bullying na escola: "Já vi meu primo chamando o meu amigo de carequinha do vovô". Outro aluno relatou que: "Todos da Escola ficam apelidando os meus colegas". 
O comportamento de bullying pode acontecer de forma direta ou indireta. O mais grave, no entanto, provoca, na maioria das vezes, traumas, descriminação e exclusão da vítima do grupo social. De acordo com Chalita (2008):

O bullying direto é mais comum entre agressores meninos. As atitudes mais frequentes identificadas nessa modalidade violenta são os xingamentos, tapas, empurrões, murros, chutes e apelidos ofensivos repetidos. O bullying indireto é a forma mais comum entre o sexo feminino e crianças menores. Caracteriza-se por ações que levam a vítima ao isolamento social. As estratégias utilizadas são difamações, boatos cruéis, intrigas e fofocas, rumores degradantes sobre a vítima e a familiares, entre outros (op.cit, p.82).

O fato dos meninos serem a maioria dos agressores não significa que suas ações sejam mais violentas que as das meninas. O bullying direto ou indireto tem consequências semelhantes. A distinção é que no direto as vítimas sabem quem são seus agressores, enquanto que no indireto isso não ocorre, porque as meninas são um pouco mais sutis em relação às suas ações.

Sobre a questão "se os alunos ao identificaram uma situação de bullying na escola" e "se eles haviam procurado a direção para relatar os fatos", dois meninos e três meninas informaram que procuraram a direção da escola, enquanto que doze meninos e seis meninas não procuram.

Dentre as respostas obtidas pelos meninos que não procuraram à coordenação/direção da escola, nenhum deles justificou as suas respectivas respostas; já entre as meninas que procuraram à coordenação/direção da escola, apenas uma justificou a sua resposta: "Sim. Um menino me chamou de 'cabueta'", por isso a mesma resolveu procurar à coordenadora da escola.

É importante destacar que na maior parte das ocorrências, dos casos de bullying, os jovens envolvidos não contam o que está acontecendo para nenhum adulto. Na maioria das vezes não falam por medo de que suas queixas não sejam levadas a sério e que os agressores não sejam punidos. Por isso é de fundamental importância que os pais e os professores precisam estar atentos aos "sinais" para identificar as situações de violência dessa prática e, se tiver caso de denúncia de um dos alunos, não desconsiderá-la e sim tomar medidas para ajudar os alunos da melhor forma possível.

A questão que indagou sobre a opinião dos alunos relativa ao "porque ocorre o bullying na escola", os alunos responderam na sua maioria que: "existem alunos que são indisciplinados, gostam de bater, apelidar, xingar e ofender os pais dos colegas que sofrem bullying, porém alguns escreveram a existência de preconceito (mas não justificou que tipo de preconceito). 
Segundo Meier (2013, p. 15) "[...] o problema ocorre quando surge o bullying, que é nada menos que uma forma de desrespeito às diferenças".

Julga-se que a escola é o lugar onde o bullying pode crescer de forma indiscriminada. Se não for interditado em tempo hábil, podendo trazer prejuízos não só para o ambiente escolar, como também para toda a comunidade.

A escola precisa ser vista como um ambiente seguro, como também de muita aprendizagem; deve ser um lugar onde as crianças adquiram um desenvolvimento saudável. Esse ambiente escolar jamais deveria ser associado a alguns sentimentos como: tristeza ou medo. É por essa razão que o bullying não pode ter espaço nas instituições de ensino.

$\mathrm{Na}$ visão dos alunos de "como a escola poderia agir na coibição do bullying", houve semelhança das respostas, sendo elas: "a escola deveria suspender os alunos", "a escola deveria colocar os alunos de castigo", a "escola deveria chamar os pais".

Um aluno respondeu que: "a escola deveria chamar o Conselho Tutelar", já outro relatou que: "a escola deveria chamar a polícia". A partir dessas falas, podemos observar que os alunos não reconhecem a escola como uma instituição com autoridade para procurar solucionar o problema do bullying no espaço escolar e, sugerem que procurem as demais instituições por meio de outras autoridades para poder solucionar o problema em questão.

As escolas devem desenvolver programas ou estratégias para a redução ou até mesmo prevenção para essa problemática. Para isso é preciso ter a união e cooperação com a comunidade escolar, os pais e os alunos para combater esse fenômeno. Essas ações de enfrentamento têm mais chance de apresentar bons resultados, quando são desenvolvidas em conjunto.

Quando não há intervenções e programas preventivos efetivos contra o bullying, o ambiente escolar torna-se totalmente contaminado e sujeito a diversas consequências. Alguns alunos que testemunham situações de bullying podem perceber que o comportamento agressivo dos que o praticam não Ihes traz nenhuma consequência, sendo com isso levados a adotá-lo também. (GUARESCHI, 2008, p. 61).

É muito importante o envolvimento de todos da comunidade, de modo especial, dos próprios alunos nesse combate que amedronta as escolas em geral. A união da escola em parceria com os professores, coordenadores, diretor e bibliotecário/o profissional da biblioteca junto à família poderá ser um caminho para que esse quadro seja revertido um dia, pois esse trabalho tem que ser sempre contínuo. 
Em presença desse quadro de desvios de valores fundamentais para a formação do indivíduo, o bullying é visto como um meio para se atingir as lideranças e o reconhecimento dos colegas. Consequentemente os alunos/vítimas sofrem. A escola deve e precisa vigiar constantemente seus alunos, construindo assim um ambiente voltado para a paz dentro das salas de aulas.

Um inimigo é mais facilmente derrotado quando o conhecemos bem. Desta forma, devemos avaliar o que fazer para que possamos vencer essa guerra contra esse fenômeno que a cada dia se mostra alarmante. É importante que identificarmos suas causas e consequências, como também os perfis dos alunos/vítimas e dos alunos/agressores. De maneira nenhuma podemos ficar estagnados, acreditando que essa prática não vai acontecer. Por isso é sempre importante ressaltar que precisamos ficar alerta aos sinais das crianças, identificando o problema e ajudando logo para a criança não tomar atitudes drásticas contra o agressor.

O bullying é um problema que existe em todas as escolas. Ainda assim, poucas têm consciência de sua existência ou mesmo das graves consequências advindas desses atos cruéis e intimidadores. Em muitos casos, ele é confundido com indisciplina ou mesmo brincadeiras próprias da idade ou, ainda, com agressões corriqueiras, causais. Diante desse quadro, quais as ações educacionais que podem ser adotadas para minimização do bullying nas escolas? (PEREIRA, 2011, p. 9-10).

Na última questão foi solicitado aos alunos que respondessem apenas sim ou não relativo à "contribuição do profissional que atua na biblioteca da escola em auxiliar a coibir o bullying", oito meninos e duas meninas responderam que sim, e seis meninos e sete meninas responderam que não.

Assim, de acordo com as respostas dos alunos, o profissional da biblioteca pouco contribui para coibir o bullying na escola. Uma aluna disse que a responsável da biblioteca (que é uma professora) pode ajudar sim, "mas ela não faz nada". Já outro aluno disse que o profissional da biblioteca pode "tirar todos os alunos das salas que fazem isso (bullying) e levar para biblioteca", como se os alunos vissem aquele ambiente a (biblioteca) lugar de castigo.

[...] a escola é corresponsável. O código de defesa do consumidor afirma que uma prestadora de serviços (a escola, no caso) é responsável legal pela qualidade do serviço prestado e por tudo o que acontece dentro de suas dependências. Não há como a escola tentar se eximir alegando que "avisou aos alunos que praticas de bullying são proibidas". Não basta avisar: é necessário coibir. Há várias decisões judiciais que obrigam escolas e universidades a indenizar vitimas de ações de bullying praticadas em suas dependências ou até mesmo fora delas, pois foi comprovada a extensão dos atos. (MEIER, 2013, p. 44). 
É importante que o profissional que atua na biblioteca participe diretamente na coibição do bullying, planejando, junto com corpo docente da escola, atividades e gerando informações pertinentes que possibilitem aos alunos maiores esclarecimentos sobre as causas e consequências dessa atividade.

Conforme a literatura pesquisada, o bibliotecário pode fazer intervenções que auxiliam o trabalho dos professores, coordenadores e diretores junto com os pais para coibir esse fenômeno. O bibliotecário para atuar em uma biblioteca escolar é preciso que ele deixe para trás seu papel passivo e isolado, chamando a atenção para um novo perfil bastante dinâmico, questionador de aprendizagem ao logo de sua carreira e como também de sua vida para com os alunos.

A biblioteca escolar possui um papel fundamental no processo de incentivo e formação de leitores. Ela deve se impor, como unidade de informação, deixando de ser uma mera espectadora para ser uma agente de disseminação não só da leitura, como de outras atividades. Isso só é possível ao bibliotecário tomando uma postura de mediador junto aos alunos.

Conforme Meier (2013, p. 44-45) "[...] a escola precisa ser proativa e atuar de forma que atos de bullying jamais aconteçam. Escolas são instituições educativas, e não punitivas. Cadeias e presídios punem, escolas educam".

A escola não pode esperar que ocorram os casos de bullying para tomar alguma medida contra o problema, agindo por meios de punições, reuniões com pais dos alunos. Ela precisa agir sempre para assim evitar o avanço dessa problemática; precisa está alerta junto aos seus alunos, observando-os se está acontecendo a prática do bullying para tomar as medidas necessárias para a sua coibição.

\section{CONSIDERAÇÕES FINAIS}

Ao definir o Locus do ensaio percebe-se que a inexistência do profissional bibliotecário infringe dois aspectos: a legislação sobre a obrigatoriedade de se manter um profissional da área na biblioteca escolar e também o remanejamento inadequado de um professor que se encontra com problemas de saúde em ambiente fora de sala de aula.

Esse problema não é localizado, mas reflete também a missão designada a biblioteca, encontrando-se aquém do esperado, distanciando as possibilidades de mediação entre o profissional bibliotecário e os demais profissionais que atuam no ambiente escolar para coibição do bullying. 
O bullying é visto como um problema de saúde pública. Aqueles que praticam ou sofrem bullying carregam sequelas físicas e mentais, as vítimas tem um desempenho escolar menor em relação aos colegas de sala e tende a não gostar do ambiente da escola. São mais propensos a abandonar os estudos.

Os professores, coordenadores e diretores, junto com o bibliotecário, precisam entender que o bullying acontece a qualquer momento e com qualquer aluno. É preciso desenvolver um olhar mais observador e atento para com os alunos. Sendo assim, deve atentar-se para sinais de violência, procurando neutralizar os agressores, bem como assessorar as vítimas e transformar os outros alunos em principais aliados contra o bullying, para que possam diminuir as ocorrências dentro do contexto escolar, pois todos agindo contra essa problemática irá ter uma diminuição gradativa.

É importante mencionar que as atividades propostas pelos programas de prevenção ao problema analisado possibilitam a atuação frequente, não só do espaço físico da biblioteca escolar, mas a participação do bibliotecário para tentar minimizar junto com a sociedade e o corpo docente da escola.

\section{REFERÊNCIAS}

ABRAPIA. Bullying. Disponível em: <www.bullying.com.br.>. Acesso em: 10 jun. 2015.

ANTONIO, Deise; MORAES, João Ernesto de. O Professional da informação na sociedade do conhecimento: aspectos e proposta para a sua atuação na mediação da informação. São Paulo: Ibersid, 2008.

CALDIN, Clarice Fortkamp. Reflexões acerca do papel do bibliotecário de biblioteca escolar. Revista ACB: Biblioteconomia em Santa Catarina, Florianópolis, v. 10, n. 2, p. 163-168, 2005. Disponível em $<$ http://www.brapci.ufpr.br/documento.php?dd0=0000008085\&dd1=7fba9>. Acesso em: 10 jun. 2013.

CHALITA, Gabriel. Pedagogia da amizade: Bullying: o sofrimento das vítimas e dos agressores. São Paulo: Gente, 2008.

EDUVIRGES, Joelson Ramos. A importância da biblioteca escolar para incentivar o hábito da leitura. Especialização em Formação de Leitores da Faculdades Integradas de Jacarepaguá. Polo Teresina, 2012. 
FANTE, Cleo. Fenômeno Bullying: como prevenir a violência nas escolas e educar para a paz. 2. ed. Campinas: Verus, 2005. 224 p.

FANTE, Cléo. Programa de Enfrentamento ao Bullying no ambiente escolar. Campanha aprender sem medo. São Luís. Unigraf, 2010. Disponível em: <http://www.plan.org.br/publicacoes/download/cartilha_enfrentamento_bullying.pdf> Acesso em: 10 de jun. 2015.

\section{FEDERAÇÃO INTERNACIONAL DAS ASSOCIAÇÕES DE BIBLIOTECÁRIOS E} BIBLIOTECAS. Manifesto IFLA/UNESCO para biblioteca escolar. Traduzido por Neusa Dias de Macedo. São Paulo, 2002. Disponível em: <http://www.ifla.org/VII/s11/pubs/portuguese-brazil.pdf>. Acesso em: 20 jul.2013.

GUARESCHI, Pedrinho A.; SILVA, Michele Reis da. (coord.) Bullying: mais sério do que se imagina. Porto Alegre: Edipucrs, 2008.

LOPES NETO, Aramis A. Bullying: comportamento agressivo entre estudantes. Jornal Pediatria, Porto Alegre, v. 81, n. 5, p. 164-172, nov. 2005.

LOPES NETO, A.; SAAVEDRA, L.H. Diga não para o bullying: programa de redução do comportamento agressivo entre estudantes. Rio de Janeiro: ABRAPIA, 2003.

LYRA, Ana Rosa Nune; PAZ, Lívia Maria Martins Coelho. Bullying: marcas que não se apagam. Maceió: 2009.

MEIER, Marcos; ROLIM, Jeanine. Bullying sem blá-blá-blá. Curitiba: Intersaberes, 2013, p. 171.

MORAES, Scheila Conrado de. Biblioteca escolar e a prevenção ao bullying escolar. Florianópolis, 2014.

PEREIRA, Beatriz O. Para uma escola sem violência: estudo e prevenção das criticas agressivas entre crianças. Fundação Caloste Gulbenkian. Fundação para Criança e a Tecnologia. Ministério da Ciência e tecnologia. Porto: Ed. Imprensa Portuguesa, 2002.

PEREIRA, Sônia Maria de Souza. Bullying e suas implicações no ambiente escolar. 3 ed. São Paulo: Paulus, 2011.

PIMENTEL, Graça; BERNARDES, Liliane; SANTANA, Marcelo. Biblioteca escolar. Brasília: Universidade de Brasília, 2007. 117 p. Disponível em:

<http://portal.mec.gov.br/seb/arquivos/pdf/profunc/biblio_esc.pdf>. Acesso em: 26 de nov. 2013. 
QUERINO, Késia de Souza. O bibliotecário de biblioteca escolar como agente mediador e disseminador da leitura. Florianópolis: 2013.

SANTANA, Edésio T. Bullying e cyberbullying: agressões dentro e fora das escolas: teoria e prática que educadores e pais devem conhecer. São Paulo: Paulus, 2013.

SILVA, Fabiano Couto Corrêa da. Bibliotecários especialistas: guia de especialidade e recursos informacionais. Brasília: Thesaurus, 2005.

SILVA, Robson José. Formar leitores na escola. In: SILVA, Rovilson José; BORTOLIN, Sueli (Org). Fazeres cotidianos na biblioteca escolar. São Paulo: Polis, 2006. p.73-78.

VALENTIM, Marta Lígia Pomim (Coord.). O profissional da informação: formação, perfil e atuação profissional. São Paulo: Polis, 2000. 